\title{
Joint Data Management on ICDP Projects and IODP Mission Specific Platform Expeditions
}

\author{
by Ronald Conze, Hans-Joachim Wallrabe-Adams, \\ Colin Graham, and Frank Krysiak
}

\section{Introduction}

Data management in the Integrated Ocean Drilling Program (IODP) and the International Continental Scientific Drilling Program (ICDP) supports two functions: firstly, the capture of drilling and scientific data and secondly, the longterm storage and dissemination of these data. The data capture in both ICDP projects and IODP-Mission Specific Platform (MSP) expeditions takes place in two phases. During the drilling phase, drilling, curation, logging, and basic scientific data are captured at the drill site. In the postdrilling phase the detailed measurements, descriptions, images and $\log$ data for the split cores are captured within a laboratory setting and the data subsequently transferred to the long-term data storage system. Here we show how a flexible and modular designed information system has been developed over the course of continental and ocean drilling projects.

\section{The Drilling Information System DIS}

Development of the Drilling Information System (DIS) by the Operational Support Group (OSG) ICDP at the GeoForschungsZentrum (GFZ) Potsdam began in 1996. The first field test was conducted in 1998 during the ICDP Long Valley Exploratory Well project. Since then, the DIS has been used by many ICDP-supported projects and has been improved and adapted to match new requirements.

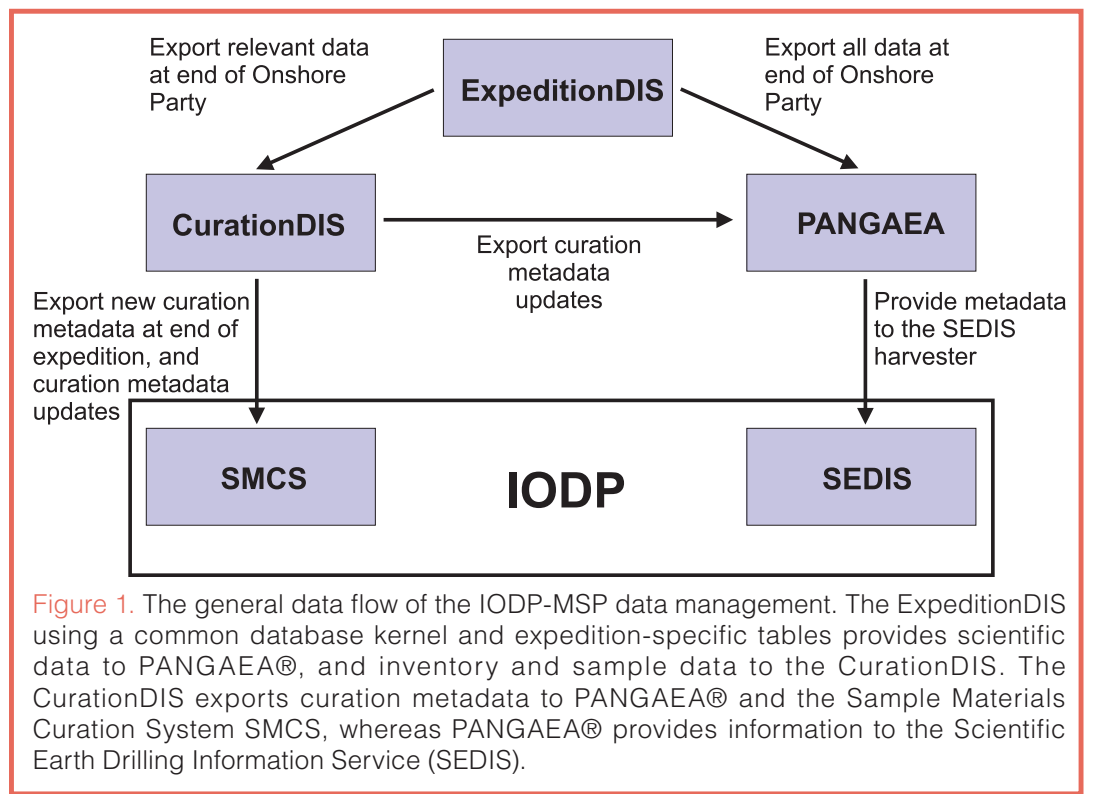

ICDP lake drilling projects and IODP-MSP expeditions have quite similar requirements for a data management system. It has to be mobile, easy to configure and capable of being deployed quickly on small- to medium-sized drilling platforms of opportunity. It also has to be suitable for deploying in one or more laboratories during the post-drilling data capture phase. The ExpeditionDIS was especially designed to meet these requirements (Conze et al., 2004).

Development of the ExpeditionDIS for IODP-MSP expeditions began in 2002, and the first version was used for Expedition 302 - Arctic Coring Expedition (ACEX) in 2004. It was then modified and enhanced for IODP Expedition 310-Tahiti Sea-Level in 2005, and will be used for IODP Expedition 313-New Jersey Shallow Shelf scheduled for 2007.

Another component of the DIS, the CurationDIS has been developed for use in the Bremen Core Repository (BCR, Bremen, Germany) to manage cores and samples from IODP-MSP expeditions. It will be linked into the IODP Sample Materials Curation System (SMCS) currently under development within IODP (Fig. 1).

\section{Technical Details and Data Model}

The DIS allows the user to build customized data management systems and environments for drilling projects. It has a graphical user interface, a Web interface, tools to define, generate, and administer data structures, and other elements necessary for a drilling information management system. A central component of the DIS is a set of generic data structures (templates) and dictionaries for scientific drilling purposes. These can be adapted and modified to meet specific project needs, (e.g., cuttings data, hard-rock core data, long-term monitoring data and engineering data). The graphical user interface is used to generate input forms, report templates and data views. Other tools allow the user to build specific data import modules, and to generate customized Web-pages documenting progress during the project. To visualize data, the DIS generates Scalable Vector Graphics, which are used in tools such as the Downhole- 
Measurement-Profile-Builder and the LithologicalProfile-Builder.

The deployment of the DIS is highly scalable, ranging from a standalone installation on a laptop with runtime versions of MS Access and MS SQL Server, to a client-server installation with one or more DIS database servers and several client computers. The client computers can either be connected directly to the DIS server on the network, or through the XDIS web interface.

A typical setup for a project requires one DIS server computer hosting the database and several DIS clients for data input and data retrieval (Fig.2). These are connected to form a local intranet. The

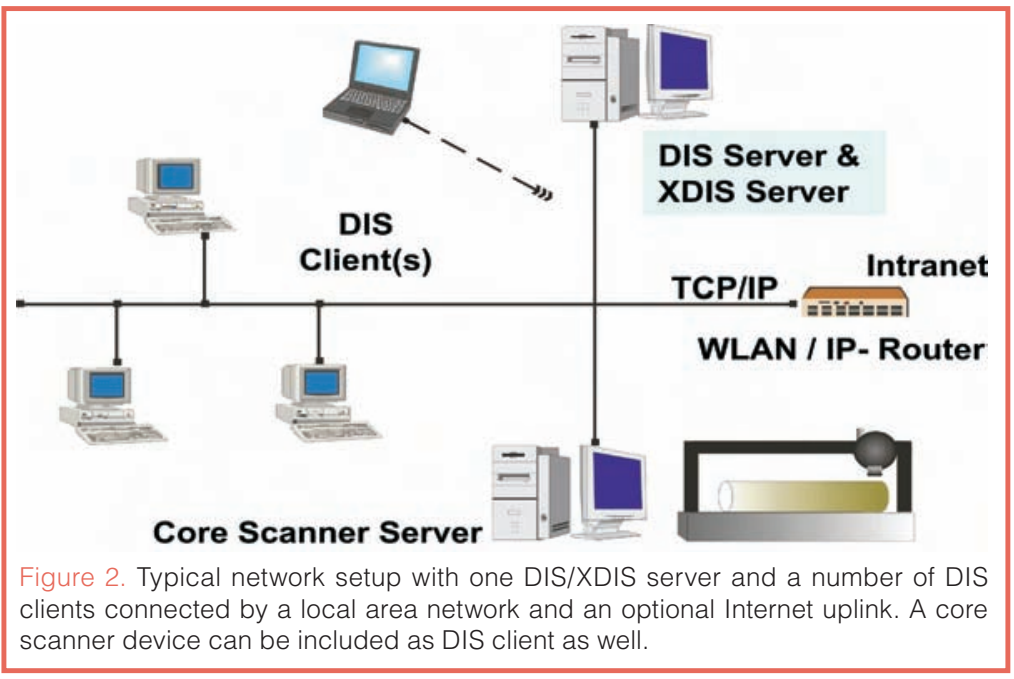
DIS server can also be accessed via the Internet if a connection is available. Optical core scanning devices such as the DMT CoreScan ${ }^{\circledR}$ Color or the smartcube ${ }^{\circledR}$ smartCIS $^{\text {TM }}$ (Camera Image Scanner) can be integrated into the network to allow core images and related metadata to be loaded directly into the database. Other data collected by the GEOTEK MultiSensor CoreLogger (MSCL) can be uploaded into the database through special interfaces.

The ExpeditionDIS data model is compatible with the other IODP databases, PANGAEA ${ }^{\circledR}$ and the lake coring database LacCore (University of Minneapolis, Minn., U.S.A.). Because of this compatibility, ICDP adopted the same data model for its land and lake drilling projects in 2005 .

\section{Experience from Drilling Expeditions}

The ExpeditionDIS has been used for three expeditions: IODP Expedition 302 - ACEX in 2004, IODP Expedition 310 - Tahiti Sea Level in 2005 and the ICDP Lake Petén Itzá Scientific Drilling Project in 2006. The offshore drilling phase of Expedition 302 was unique in terms of both the working environment and the use of multiple platforms (Moran et al., 2006). At the same time, it was a challenging testbed for the data management system, as it was the first deployment of the ExpeditionDIS requiring capture, management and sharing of data between the Vidar Viking and the Oden (Fig. 3). On the Vidar Viking drillship, cores and samples were curated, whole cores were logged using the GEOTEK MSCL and ephemeral properties were measured. The core catchers and selected samples were transferred to the Oden where they were described and photographed.

ExpeditionDIS systems were installed on both ships, each with its own DIS server and DIS clients connected to the local area network. Both systems were capable of working independently, but were synchronized, with database replication occurring between the ships using the wireless communications network that linked all three ships in the

fleet. During the onshore phase at the Bremen Core Repository (BCR) in November 2004 data from 340 m of split core-sections and more than 8,000 samples were efficiently captured by the ExpeditionDIS (Fig. 4). The offshore and onshore data acquisition continued seamlessly despite the very different environmental conditions on the ships and in the core repository. Based on the ACEX experience, the ExpeditionDIS was amended with new data tables, dictionaries, forms, and reports to support coral-reef drilling during IODP-MSP Expedition 310 to Tahiti. Thirty-seven holes were drilled at twenty-two sites around Tahiti recovering 632 m of coral-reef core (Expedition 310Scientists, 2006). During the onshore phase in Bremen the split cores were analyzed and described in detail and more than 12,500 samples were taken for further measurement and analysis, all supported by ExpeditionDIS.

The ICDP Lake Petén Itzá Scientific Drilling Project (Hodell et al., 2006) used the same ExpeditionDIS system as used by the Tahiti expedition. Two project scientists were trained as on site DIS-administrators during a five-day course. The sampling and additional measurements were performed using the core inventory documented by the ExpeditionDIS during the drilling phase.

\section{Long-Term Archives}

The concept of the DIS is that it is used only during the lifetime of a drilling project, and that on completion of the project the data are transferred to a long-term data management and access system. The ECORD Science Operator (ESO) selected the PANGAEA® ICSU World Data Center for Marine Environmental Sciences (WDC-Mare http://www.wdc-mare.org; Diepenbroek et al., 2002) as the long-term archive for IODP-MSP data (Fig. 1). The data for the IODP-MSP expeditions are currently accessible via a data portal (http://iodp.wdc-mare.org). This MSP data as well as data from other IODP drilling platforms will be accessible through the Scientific Earth Drilling Information Service's (SEDIS) distributed search capability underpinned by a common metadata model (http://sedis.iodp.org/, Miville 
et al., 2006). Data from ICDP projects are transferred to the Scientific Drilling Database (SDDB, http://www. scientificdrilling.org) operated by the Data Center of GFZ Potsdam, Germany (See article on page 30-31, Klump and Conze, 2007).

\section{Further Developments and Conclusions}

The ExpeditionDIS has been proven to work as a robust, easy to maintain and use, on-site data capture and management system. Several additional data management components are planned. These include a visual core description module, a stratigraphic information module and data exchange tools.

\section{Acknowledgements}

The development of the ICDP Drilling Information System was funded by the GeoForschungsZentrum Potsdam, the German Research Foundation and ICDP. ExpeditionDIS and CurationDIS were financed by European Consortium for Ocean Research Drilling (ECORD) and ICDP.

\section{References}

Conze, R., Krysiak, F., Graham, C., and Wallrabe-Adams, H.-J., 2004. Data modeling, development, installation and operation of the ACEX offshore drilling information system for the mission specific platform expedition to the Lomonosov Ridge, Arctic Ocean. AGU 2004 Fall Meeting, Poster GC51D1084, San Francisco , Calif., U.S.A.

Diepenbroek, M., Grobe, H., Reinke, M., Schindler, U., Schlitzer, R., Sieger, R., and Wefer, G., 2002. PANGAEA - an information system for environmental sciences. Comp. Geosci., 28:1201-1210. doi:10.1016/S0098-3004(02)00039-0

Expedition 310 Scientists, 2006. Tahiti sea level: the last deglacial sea level rise in the South Pacific. Offshore drilling in Tahiti

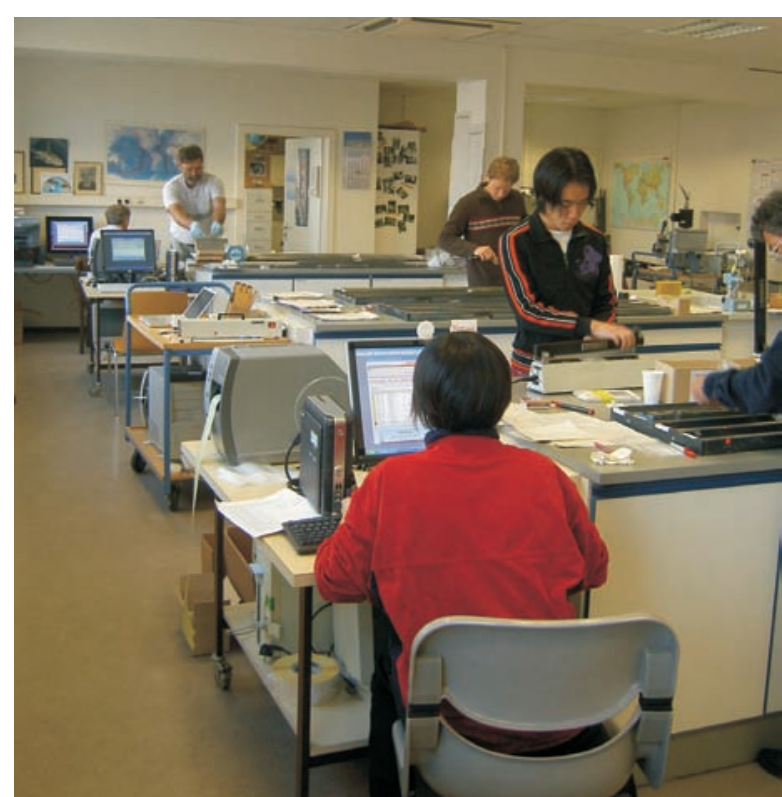

Figure 4. Documentation and sampling of ACEX cores at the former Bremen Core Repository using the ACEX ExpeditionDIS. Several DIS clients were used for the input of visual core description and sample curation data.

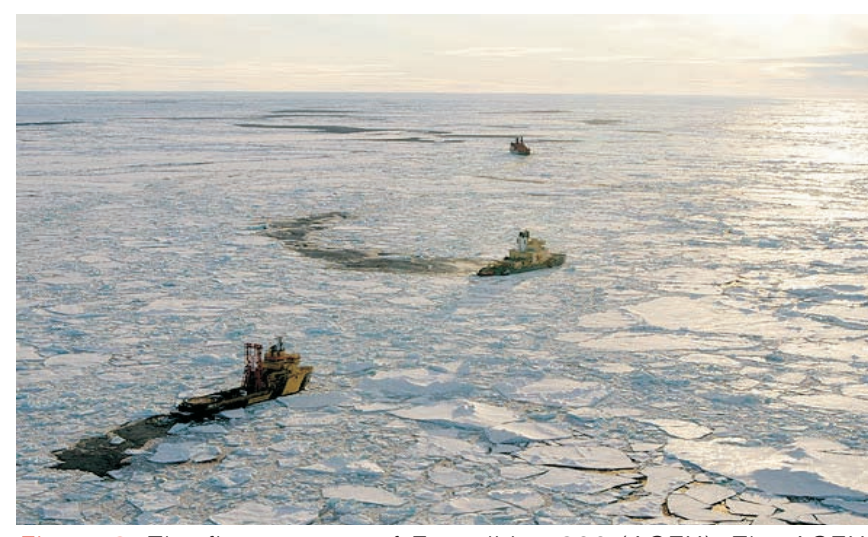

Figure 3. The fleet convoy of Expedition 302 (ACEX). The ACEX ExpeditionDIS was installed on both the drill ship Vidar Viking in front, and the Oden serving as icebreaker and hosting laboratories in the middle, synchronized via a WLAN connection. The icebreaker Sovetskiy Soyuz is in the background.

(French Polynesia). IODP Prel. Rept., 310, doi: 10.2204/iodp. pr.310.2006.

Hodell, D., Anselmetti, F., Brenner, M., Ariztegui, D., and the PISDP Scientific Party, 2006. The Lake Petén Itzá scientific drilling project. Sci. Drill., 3:25-29. doi:10.2204/iodp.sd.3.02.2006.

Klump, J., and Conze, R., 2007. The Scientific Drilling Database (SDDB) - data from deep Earth monitoring and sounding. Sci. Drill., 4:30-31. doi:10.2204/iodp.sd.4.06.2007

Miville, B., Soeding, E., and Larsen, H.Ch. (2006): Data management in IODP. Sci. Drill., 2: 48-49.

Moran, K., Backman, J., and Farrell, J.W., 2006. Deepwater drilling in the Arctic Ocean's permanent sea ice, Proc. IODP, 302, 13p, doi:10.2204/iodp.proc.302.106.2006.

\section{Authors}

Ronald Conze, Operational Support Group ICDP, GeoForschungsZentrum Potsdam, Telegrafenberg A34, D14473 Potsdam, Germany, e-mail: conze@gfz-potsdam.de Hans-Joachim Wallrabe-Adams, MARUM, University of Bremen, Leobener Str., D-28359 Bremen, Germany.

Colin Graham, British Geological Survey Edinburgh, ESOECORD Science Operator, Murchison House, West Mains Road, Edinburgh EH9 3LA, Scotland, U.K.

Frank Krysiak, smartcube GmbH Berlin, Puschkinallee 48, D-12435 Berlin, Germany.

\section{Related Web Links}

http://www.icdp-online.org

http://www.iodp.org

http://www.ecord.org

http://www.wdc-mare.org

http://iodp.wdc-mare.org

http://sedis.iodp.org

http://www.scientificdrilling.org

http://www.smartcube.de

\section{Figure Credits}

Fig. 3. Photo by Martin Jakobsson Fig. 4. Photo by Ronald Conze. 